US Army Corps

of Engineers ${ }_{\circledast}$

Engineer Research and

Development Center

Environmental Quality/Installations (EQI)

\title{
Conceptual Development and Testing of a Chitosan/Graphene Oxide (CSGO) "Bandage" to Isolate and Remove Chemical Contamination from Surfaces
}

Victor F. Medina, Chandler Noel, and Jose Mattei-Sosa

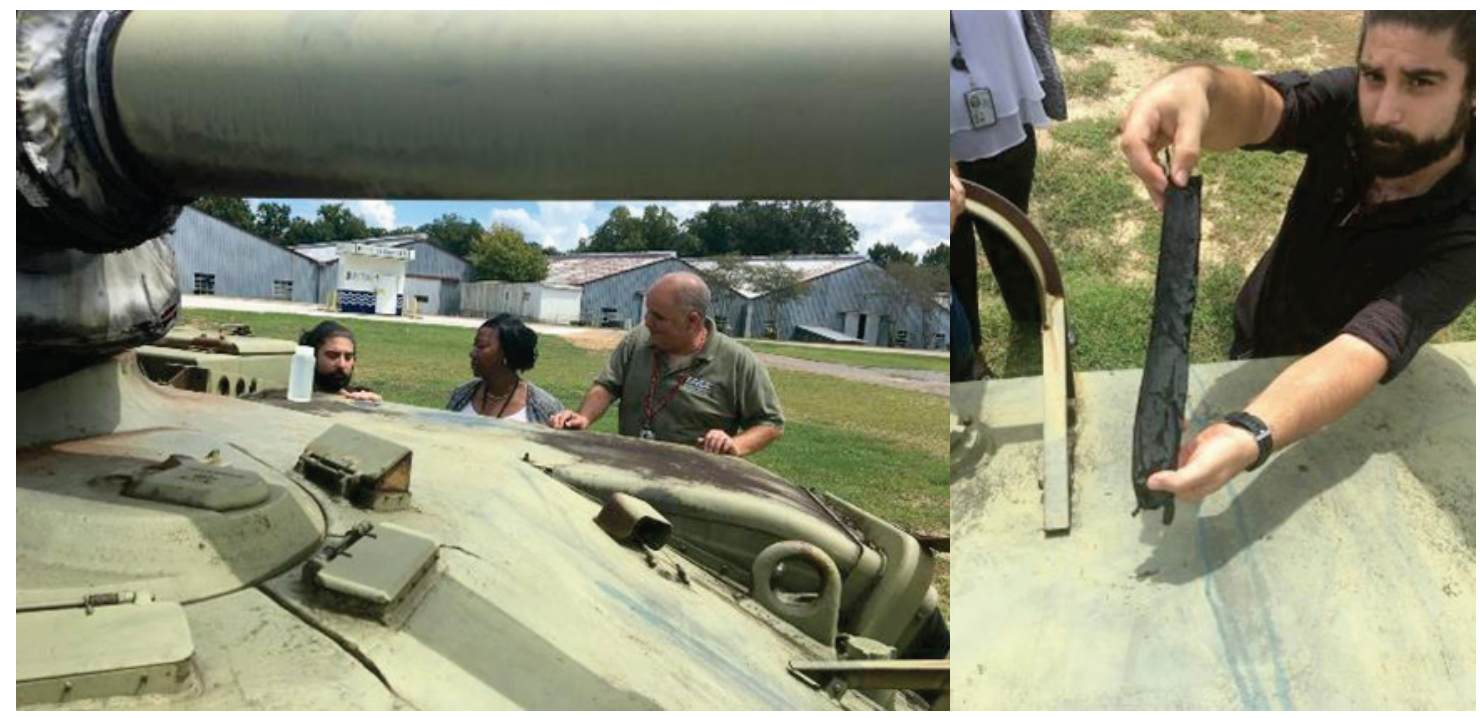


The U.S. Army Engineer Research and Development Center (ERDC) solves the nation's toughest engineering and environmental challenges. ERDC develops innovative solutions in civil and military engineering, geospatial sciences, water resources, and environmental sciences for the Army, the Department of Defense, civilian agencies, and our nation's public good. Find out more at www.erdc.usace.army.mil.

To search for other technical reports published by ERDC, visit the ERDC online library at https://erdc-library.erdc.dren.mil. 


\title{
Conceptual Development and Testing of a Chitosan/Graphene Oxide (CSGO) "Bandage" to Isolate and Remove Chemical Contamination from Surfaces
}

Victor F. Medina and Jose Mattei-Sosa

\author{
U.S. Army Engineer Research and Development Center (ERDC) \\ Environmental Laboratory (EL) \\ Waterways Experiment Station, 3909 Halls Ferry Road \\ Vicksburg, MS 39180-6199 \\ Chandler Noel \\ Mississippi College \\ Department of Chemistry \\ 200 Capitol Street \\ Clinton, MS 39056
}

Final Report

Approved for public release; distribution is unlimited.

\footnotetext{
Prepared for Headquarters, U.S. Army Corps of Engineers Washington, DC 20314-1000

Under Work unit 33143, P2 455017
} 


\section{Abstract}

This study describes the conceptual development and testing of a protective "bandage" prepared of a composite chitosan/graphene oxide (CSGO) material that can be applied over surfaces to isolate contamination, such as that occurring from a chemical weapon attack. The bandage can be applied either as a wet dispersion or as a dry, preset membrane. Dry bandage application can be implemented by wetting the material with acetic acid and setting on the surface, or the bandage can placed on the surface and acetic acid brushed over the bandage. The bandage isolates the contaminant by covering the contaminated area and preventing exposure, or by absorbing the contaminant into its structure. The bandage can then be removed, thereby, removing the contaminant. The efficacy of this approach was demonstrated with experiments on metal coupons using methylene blue as a simulant for a contaminant. Applications on government/military vehicles are also presented. The goal is to develop a means in which vehicles contaminated with chemical agents can be treated with minimal water and returned to service quickly without any spread of contamination or damage to the vehicle.

DISCLAIMER: The contents of this report are not to be used for advertising, publication, or promotional purposes. Citation of trade names does not constitute an official endorsement or approval of the use of such commercial products. All product names and trademarks cited are the property of their respective owners. The findings of this report are not to be construed as an official Department of the Army position unless so designated by other authorized documents. 


\section{Contents}

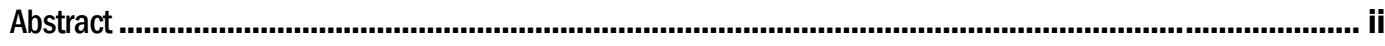

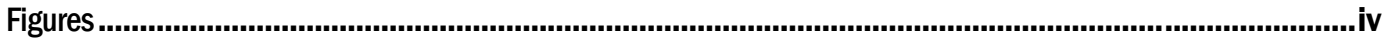

Preface............................................................................................................................................

Acronyms and Abbreviations.............................................................................................................. vi

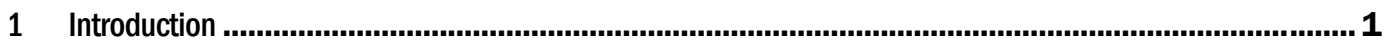

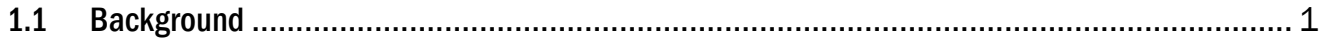

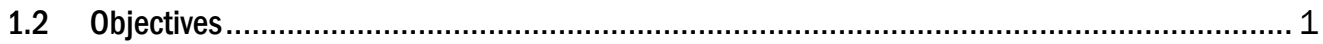

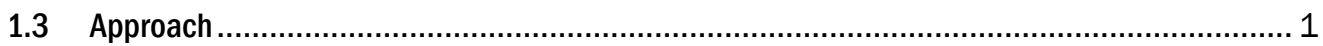

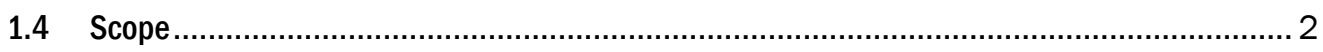

2 Laboratory Experiments............................................................................................................... 3

2.1 Preparation of the CSG0 bandage ....................................................................... 3

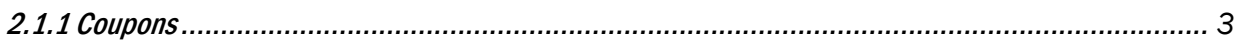

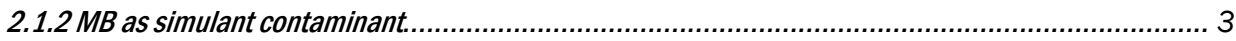

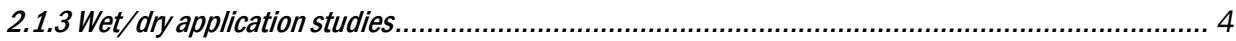

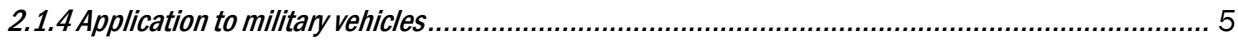

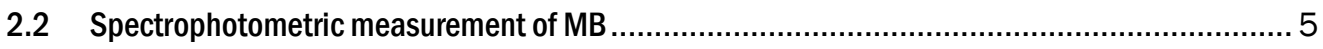

2.3 Visual estimation of bandage and MB removal........................................................... 5

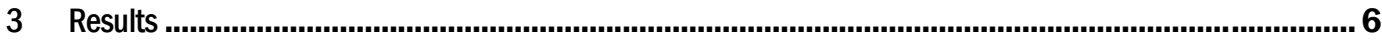

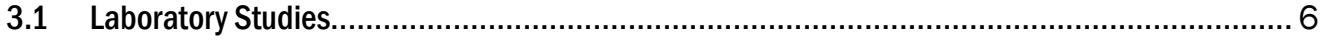

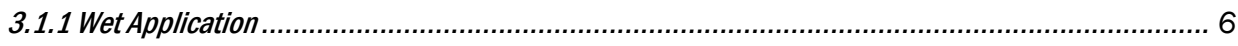

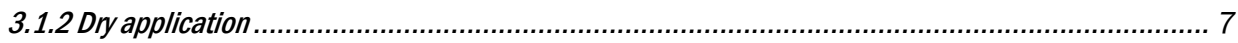

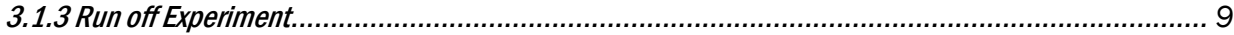

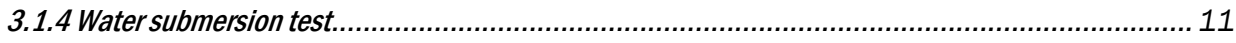

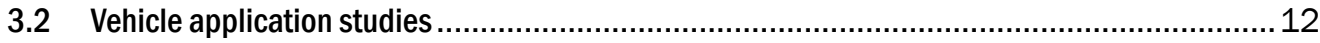

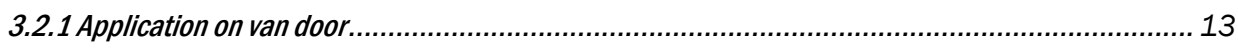

3.2.2 Bandage treatment of a HUMVEE surface ............................................................................. 13

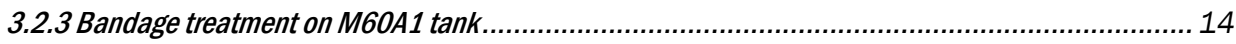

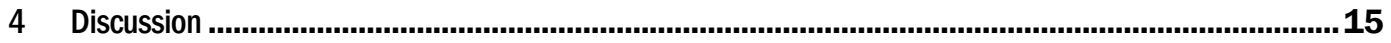

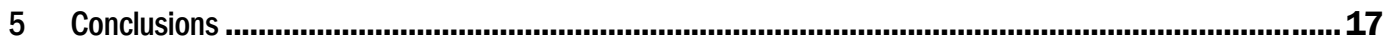

References ...................................................................................................................................18

\section{Report Documentation Page}




\section{Figures}

\section{Figures}

Figure 1. Application of pre-formed dry CSGO bandage over contaminated area, then brushing over with $5 \%$ acetic acid.

Figure 2. Wet application of CSGO Bandage (left photo). Two aluminum metal coupons were contaminated with $1 \mathrm{~mL}$ of $10 \mathrm{mg} / \mathrm{L}$ of MB, and dried on the coupon. The coupon on the left had $3 \mathrm{~mL}$ of the CSGO dispersion poured on and dried to form a bandage coating (right photo). The coupons were then submerged. The picture was taken four hours after submersion. The MB leached from the untreated coupon, but was contained on the treated coupon.

Figure 3. Dry application of a preformed CSGO membrane (left). Treated and untreated coupons with $1 \mathrm{~mL}$ of $10 \mathrm{mg} / \mathrm{L} \mathrm{MB}$ applied as a simulated contaminant (right). After four hours of submersion. The dry applied bandage curled up, however, no blue leaching was observed.

Figure 4. Application of a $5 \mathrm{in} . x 10 \mathrm{in}$. (12.7 cm x $25 \mathrm{~cm})$ CSGO bandage over a $3 \mathrm{~mL}$ dried patch of $10 \mathrm{mg} / \mathrm{L} \mathrm{MB}$ (top left). The bandage effectively covered the MB patch (top right). Upon removal of the bandage, most of the MB was removed and it was absorbed into the CSGO structure.

Figure 5. CS Bandage showing unsuccessful application.

Figure 6. Set up for the run off test. $0.5 \mathrm{~mL}$ of $\mathrm{MB}$ applied and allowed to dry to form contamination patches on two 2 in. $x 2$ in. $(5 \mathrm{~cm} \times 5 \mathrm{~cm})$ aluminum coupons. A $1.5 \mathrm{in} .(3.8 \mathrm{~cm})$ diameter CSGO bandage was applied over the MB patch on one of the coupons (left). After four hours, the bandage was removed, removing most of the MB patch (right).

Figure 7. Results of the run off study.

Figure 8. Results of the submersion test.

Figure 9. Vehicles where bandage testing was conducted. Left - Doors from a retired commuter van, Middle - HUMVEE, Right - M60A1 tank.

Figure 10. Photographs from the van door treatment study. Left - Application of $0.5 \mathrm{~mL}$ of $10 \mathrm{mg} / \mathrm{L}$ MB to form a contaminant patch, Left middle - Application of a 1.5 in. x 1.5 in. (3.8 $\mathrm{cm} \times 3.8 \mathrm{~cm}$ ) CSGO bandage, Right middle - After removal of the patch, over $90 \%$ (estimated) of the MB contaminant was removed. Right - MB adhered onto CSGO bandage after removal.

Figure 11. Photographs from the HUMVEE study. Left, shows the applied MB. Center, shows the bandage. Right, shows the spot after removal of the bandage.

Figure 12. Application to tank surface. Left, is the applied MB material, Center, the bandage covering, and the Right, is the MB after the bandage removal showing a faint outline of the original applied MB. 


\section{Preface}

This study was conducted for Environmental Quality/Installations (EQI) under work unit 33143, P2 455017 "Deployable Treatment of Decontamination Effluent."

This work was conducted by the U.S. Army Engineer Research and Development Center (ERDC), Environmental Laboratory (EL), Vicksburg, MS. At the time of publication, Dr. Andy Martin was Chief of the Environmental Engineering Branch (EPE); Mr. Warren P. Lorentz was Chief of the Environmental Processes and Engineering Division (EP). Dr. Elizabeth A. Ferguson, Senior Scientific Technical Manager (SSTM) was the lead Technical Director (EZT) of the EQI program. Mr. John Ballard was the program manager. The Deputy Director of ERDC-EL was Dr. Jack E. Davis, and the Director was Dr. Ilker R. Adiguzel.

COL Ivan P. Beckman was Commander of ERDC, and Dr. David W. Pittman was the Director. 


\section{Acronyms and Abbreviations}

\begin{tabular}{|l|l|}
\hline Acronym & \multicolumn{1}{|c|}{ Meaning } \\
\hline A & absorbance units \\
\hline CARC & Chemical Agent Resistant Coating \\
\hline CS & Chitosan \\
\hline CRBN & Chemical, Biological, Radiological, Nuclear \\
\hline CSGO & Chitosan/Graphene Oxide \\
\hline CWA & Chemical Warfare Agents \\
\hline DoD & Department of Defense \\
\hline EL & Environmental Laboratory \\
\hline EP & Environmental Processes and Engineering Division \\
\hline EPE & Environmental Engineering Branch \\
\hline ERDC & Engineer Research and Development Center \\
\hline g & gram \\
\hline GO & Graphene oxide \\
\hline HMMWV & High Mobility Multipurpose Wheeled Vehicle \\
\hline MB & Methylene Blue \\
\hline mg/L & milligram/liter \\
\hline mL & milliliters \\
\hline SSTM & Senior Scientific Technical Manager \\
\hline USACE & U.S. Army Corps of Engineers \\
\hline UV/VIS & Ultraviolet-Visible Spectroscopy \\
\hline WES & Waterways Experiment Station \\
\hline
\end{tabular}




\section{Introduction}

\subsection{Background}

Vehicle and equipment decontamination is a process of removing chemical, biological, radiological, nuclear (CBRN) contamination from military equipment and/or vehicles to protect health and return them to the battlefield. Decontamination currently uses large quantities of water, as well as surfactants and bleach (Medina et al. 2018a, 2018b). Supplying this water can be a logistical burden. Reducing logistical burdens associated with decontamination is a key goal of the Joint Chemical, Biological, Radiological, and Nuclear Contamination Mitigation Initial Capabilities Document (JCM 2011). Further, water based decontamination can take a lot of time to set up and implement. A major goal in the CBRN community is to develop and implement decontamination technologies and approaches that require minimal water use, and that can return vehicles into action very quickly (Disbrow et al. 2014).

\subsection{Objectives}

The objective of this report is to describe the development and testing of a new technology to address chemically contaminated surfaces. The technology is a bandage made of a chitosan/graphene oxide (CSGO) composite, which the Environmental Security Engineering Team, Environmental Engineering Branch (EPE), Environmental Laboratory (EL) located at the U. S. Army Engineer Research and Development Center (ERDC) had previously developed and studied as a water treatment membrane (Abolhassani et al. 2017; Medina et al. 2017). Characterization of these membranes indicate that they contain a layered structure (Medina et al. 2017). This study hypothesized that the layering can allow the contaminant to be absorbed and trapped within the membrane, providing an effective isolation functionality.

\subsection{Approach}

First, the goal of this study was to explore if CSGO materials can isolate chemical contaminants on a surface and prevent migration into aqueous media, serving as a barrier to prevent contaminant propagation. Second, this study also explored if a CSGO bandage could absorb the contaminants and remove them from the surface. Third, this study sought to develop an 
approach that could be used to rapidly return military vehicles into action after a small CBRN (Chemical, Biological, Radiological, Nuclear) exposure. Three following research questions were proposed to explore these goals:

- Question 1: Will a CSGO bandage stick to metal surfaces?

- Question 2: Can the bandage block or trap contaminants?

- Question 3: Can the bandage be removed?

The purpose of the study was to explore the process and provide a proof of concept. However, the study did have limitations that must be considered. The study was limited to a single simulant, Methylene Blue (MB). Also, the study had limited replication and relatively simple quantification methods.

\subsection{Scope}

The scope of this study included demonstrating the proof of concept for this decontamination technology. It consisted of laboratory studies and some limited field demonstrations, all using the simulant MB, instead of an actual chemical contaminant or chemical warfare agent (CWA).

The CSGO bandage was prepared using similar methods to those use to prepare filtration membranes for water treatment studies (Abolhassani et al. 2017; Medina et al. 2017). As described in Medina et al. (2017), the first step involved making a dispersion of graphene oxide (GO) and chitosan. A total of 0.3 grams (g) of GO were mixed with $1.5 \mathrm{~g}$ of chitosan in an aqueous solution. However, this study modified the formula for a water treatment membrane in Medina et al. (2017) and used 50 milliliters (mL) of deionized water for the bandage instead of $100 \mathrm{~mL}$. This adjustment resulted in a viscous solution that evaporated faster, eventually forming a thicker bandage compared to the membrane. A $1 \%$ acetic acid was added to dissolve the chitosan and allow it to bind with the GO. A study was also conducted with a bandage synthesized solely of chitosan prepared as described previously without the GO component. 


\section{Laboratory Experiments}

\subsection{Preparation of the CSGO bandage}

The CSGO bandage was prepared using similar methods to those used to prepare filtration membranes for water treatment studies (Abolhassani et al. 2017; Medina et al. 2017). As described in Medina et al. (2017), the first step involved making a dispersion of graphene oxide (GO) and chitosan. A total of 0.3 grams ( $\mathrm{g}$ ) of GO were mixed with $1.5 \mathrm{~g}$ of chitosan in an aqueous solution. However, this study modified the formula for a water treatment membrane used in Medina et al. (2017), and used 50 milliliters $(\mathrm{mL})$ of deionized water for the bandage instead of $100 \mathrm{~mL}$. This adjustment resulted in a viscous solution that evaporated faster, eventually forming a thicker bandage when compared to the membrane. A $1 \%$ acetic acid was added to dissolve the chitosan and allow it to bind with the GO. A study was also conducted with a bandage synthesized solely of chitosan prepared as described previously without the GO component.

\subsubsection{Coupons}

The laboratory studies used unpainted aluminum coupons cut into 2 in. $x$ 2 in. $(5 \mathrm{~cm} \times 5 \mathrm{~cm})$ square pieces or 2 in. $(5 \mathrm{~cm})$ radius circular pieces. Metal was chosen because most surfaces in which decontamination would likely occur include metal materials, such as military vehicles, cars, and aircraft. Also, metal has little, if any, contaminant penetration, which simplifies the study. Aluminum is widely used in military vehicles, is inexpensive, and is readily available from the machine and model shops located on the ERDC facility in Vicksburg, MS, Waterways Experiment Station (WES).

\subsubsection{MB as simulant contaminant}

The simulant contaminant MB was chosen for this study because (1) it is relatively safe to use (much of the study was conducted by a summer undergraduate student), (2) because it is a dye, it provides easy visualization of treatment effectiveness, (3) accurate measurements could be done easily using spectrophotometer, and (4) it is a reasonable simulant for organophosphate chemical warfare agents (CWA) (Brame et al. 2016).

A 10 milligram/liter $(\mathrm{mg} / \mathrm{L})$ concentration of $\mathrm{MB}$ in solution was prepared and used for the studies. Depending on the experiment, $0.5 \mathrm{~mL}$ (for most 
experiments) or $2 \mathrm{~mL}$ (for a larger band-age study) of the $10 \mathrm{mg} / \mathrm{L} \mathrm{MB}$ was applied to the surface of the coupons and allowed to dry over 24 hours to form a patch to simulate surface contamination. The strong blue color from MB made it possible to evaluate the treatment effectiveness simply by observing the color on the coupon, observation in water following submersion, or observation in rinsate water. MB concentrations were also measured using Ultraviolet-Visible Spectroscopy (UV/VIS) spectrophotometer in some experiments.

\subsubsection{Wet/dry application studies}

Wet studies involved application of the wet CSGO dispersion directly on to the MB contaminated coupon and subsequent drying to form a bandage in place. In contrast, during dry applications, the CSGO material was used to pre-form a bandage, and the dry pre-formed bandage was applied over the contaminated area after wetting with $30 \%$ acetic acid solution. The $30 \%$ concentration was used simply because it was readily available at EL. It is possible that a much lower concentration would have worked effectively, and this could be a useful area of future study.

The process of wetting the CSGO bandage with acetic acid was effective for small applications, however, increasing the bandage size required increasing the amount of acetic acid used. The larger bandages proved to be very difficult to handle while wet. Furthermore, any air movement would cause the larger CSGO bandages to fold over on to themselves, making them very hard to manage.

The team improved this by developing a new application method, which used a brush to apply acetic acid over a dry CSGO bandage placed over the contaminated site (Figure 1), instead of dipping the bandage in acetic acid and applying the wet bandage on the contaminated site. The brush method used less acetic acid, and since the bandage was applied dry, it was much easier to handle. Otherwise, the performance of wetted bandages and brushed bandages was identical (results provided in Section 3). 
Figure 1. Application of pre-formed dry CSGO bandage over contaminated area, then brushing over with $5 \%$ acetic acid.

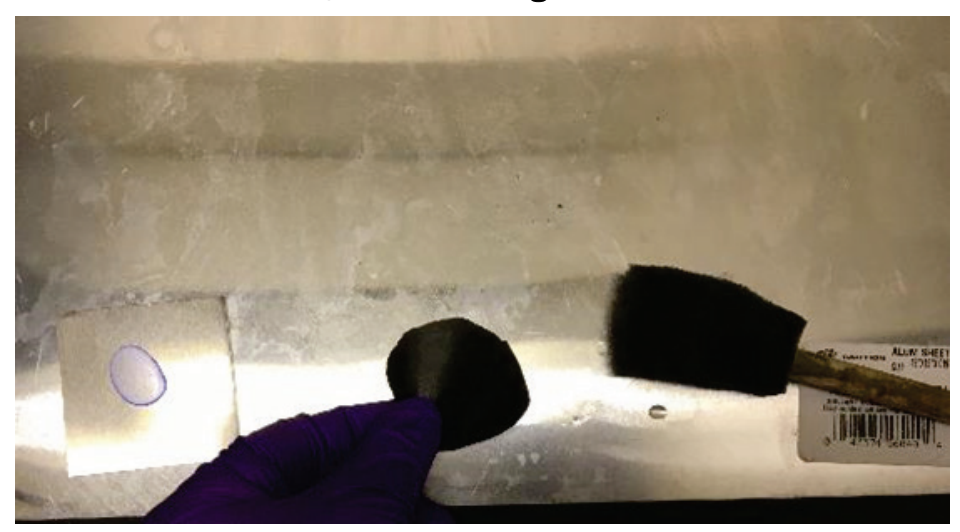

\subsubsection{Application to military vehicles}

Wet and dry applications were also studied on military vehicles. Studies were conducted by applying $10 \mathrm{mg} / \mathrm{L} \mathrm{MB}$ to the surfaces of various military vehicles on the WES. These included doors from a commuter passenger van, a High Mobility Multipurpose Wheeled Vehicle (HMMWV), and a M6oA1 tank. In these studies, rinsing with water was used as the challenge to the bandage. Specifics on these experiments are presented in the results (Section 3).

\subsection{Spectrophotometric measurement of MB}

Relative measurements of $\mathrm{MB}$ in solution were determined by measuring absorbance at $665 \mathrm{~nm}$ using an Agilent $8453 \mathrm{UV}$-Vis Spectrophotometer.

\subsection{Visual estimation of bandage and MB removal}

The dark color of the bandage, and the blue color of the MB, created strong contrasts with the metallic surfaces of the coupons. To estimate removal, this study compared before pictures with those after removal. Estimation techniques and charts used in mineralogy were then applied to estimate the removal amount (Compton 1962; Reid 1985) 


\section{Results}

\subsection{Laboratory Studies}

\subsubsection{Wet Application}

Figure 2 summarizes results of a wet application of the CSGO bandage to shield the release of the simulated contaminant (10 mg/L MB). A total of $0.5 \mathrm{~mL}$ of $10 \mathrm{mg} / \mathrm{L} \mathrm{MB}$ was applied to two aluminum metal pieces, one being a 2 in. $x 2$ in. $(5 \mathrm{~cm} \times 5 \mathrm{~cm})$ piece, and the other being a 2 in. $(5 \mathrm{~cm})$ diameter circular piece. Although the difference in the shape of the metal pieces was regrettable, they were quite similar in size. Additionally, the shape difference did not affect the MB application and presented no obvious differences in the behavior of the MB patch. The MB was air dried to form a contaminant patch. The square piece had an application of $3 \mathrm{~mL}$ of the CSGO dispersion, this was allowed to set at room temperature for about an hour. Figure 2 shows that the CSGO dried to form a bandage just a bit smaller than the 2 in. $\mathrm{x} 2$ in. aluminum square. The two pieces were then submerged in deionized water for four hours. After four hours of submersion, visual observations indicated that the shielding property of the wet applied bandage blocked the dissolution of the MB when compared to the control (Figure 2).

Figure 2. Wet application of CSGO Bandage (left photo). Two aluminum metal coupons were contaminated with $1 \mathrm{~mL}$ of $10 \mathrm{mg} / \mathrm{L}$ of $\mathrm{MB}$, and dried on the coupon. The coupon on the left had $3 \mathrm{~mL}$ of the CSGO dispersion poured on and dried to form a bandage coating (right photo). The coupons were then submerged. The picture was taken four hours after submersion. The MB leached from the untreated coupon, but was contained on the treated coupon.

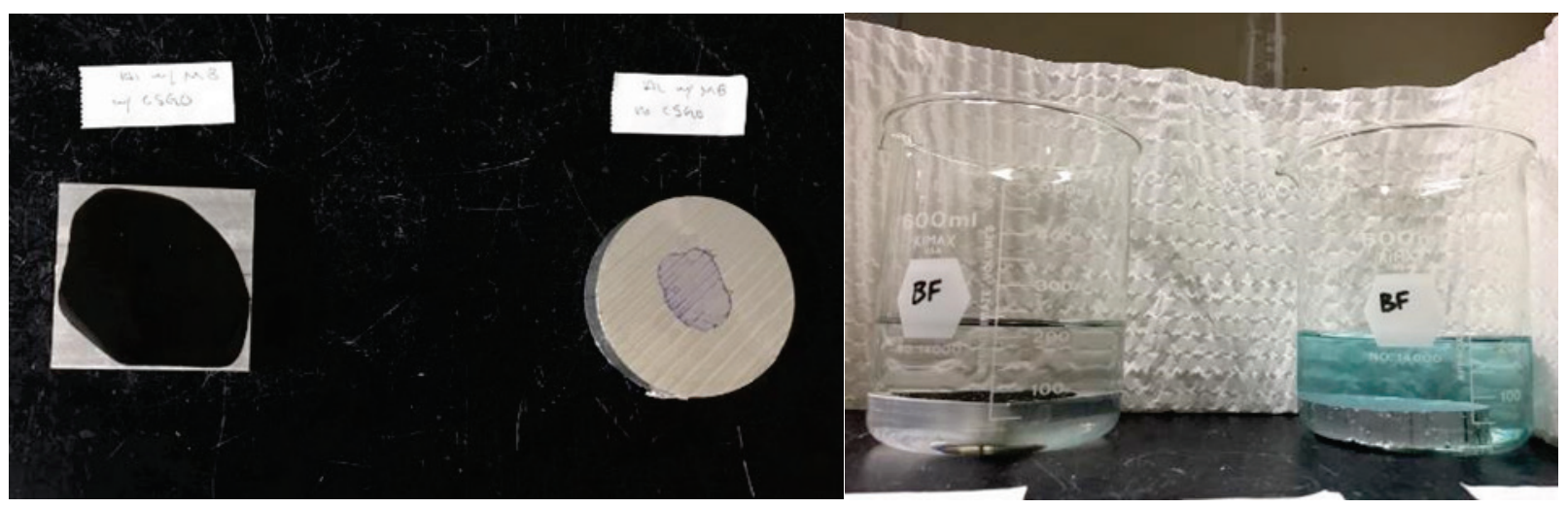




\subsubsection{Dry application}

Figure 3 shows results of the first application of a dry bandage over a coupon contaminated with $0.5 \mathrm{~mL}$ of a $10 \mathrm{mg} / \mathrm{L} \mathrm{MB}$, and the comparison of MB released into water upon submersion. As opposed to being applied as a wet dispersion, this time a dry bandage was pre-formed from the setting of $3 \mathrm{~mL}$ of CSGO suspension solution. Figure 3 shows that the CSGO dried to form a bandage (approximately rectangular, 1 in. x 1.5 in. (2.54 cm x 3.81 $\mathrm{cm})$ ). The bandage was then wetted with acetic acid and applied over the contaminated area. After four hours, the bandage application had no visible $\mathrm{MB}$ release into the submerged water, while MB was clearly visible in the control solution. This result occurred even though the bandage was peeling off. It appeared that the bandage worked by absorbing the contaminant in its structure and holding it, even when submerged.

Figure 3. Dry application of a preformed CSGO membrane (left). Treated and untreated coupons with $1 \mathrm{~mL}$ of $10 \mathrm{mg} / \mathrm{L} \mathrm{MB}$ applied as a simulated contaminant (right). After four hours of submersion. The dry applied bandage curled up, however, no blue leaching was observed.
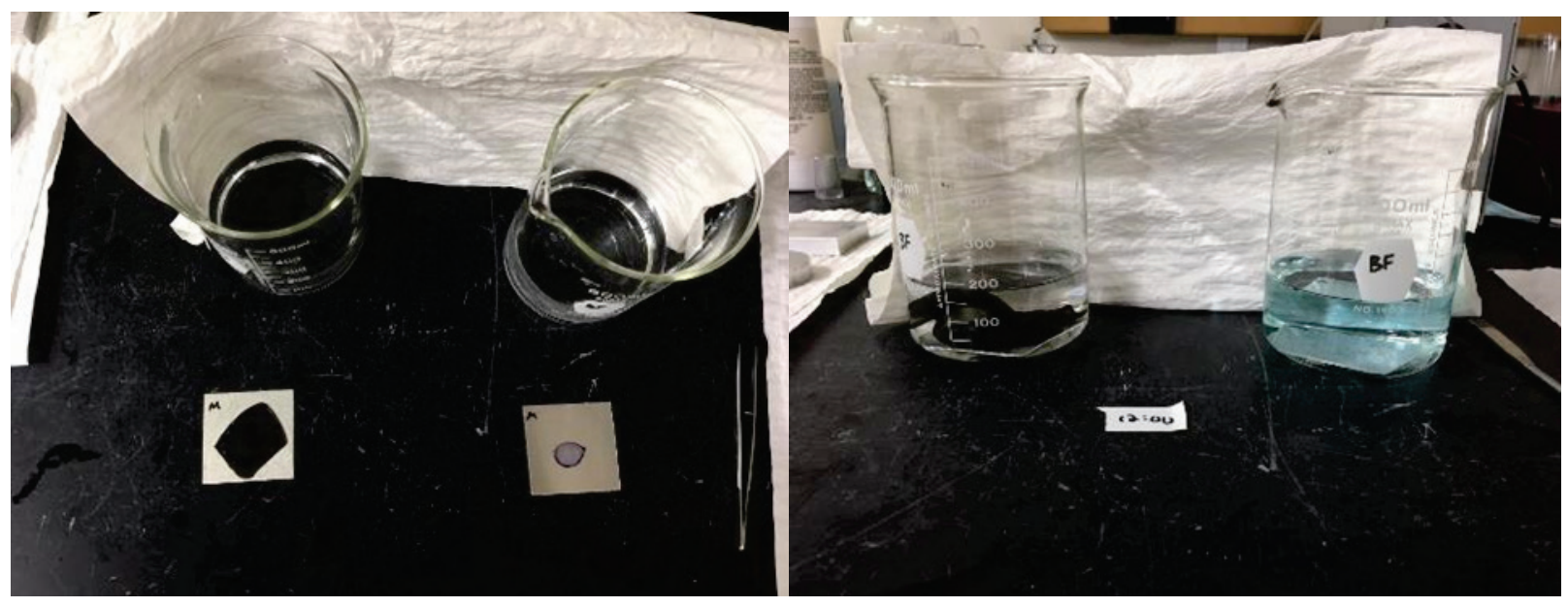

In another application, a larger 5 in. $x 10$ in. (12.7 cm x $25 \mathrm{~cm})$ CSGO bandage was applied over a dried patch of $2 \mathrm{~mL}$ of $10 \mathrm{mg} / \mathrm{L} \mathrm{MB}$ (Figure 4). The bandage was wetted with acetic acid, and was then applied to cover the MB patch. After four hours, the bandage was peeled off. Upon removal of the bandage, the majority of the dried MB patch was eliminated. There was still a small amount of MB around the edges of where the contaminant was located, however, a visual estimation concluded that $95 \%$ of the $\mathrm{MB}$ was removed. In looking over the CSGO bandage in the light, it was observed that the MB was absorbed in the bandage structure, as it looked to be inside the bandage and not in the surface. It was estimated that the bandage removed $95 \%$ of the solution that was applied. 
Figure 4. Application of a $5 \mathrm{in.} \times 10 \mathrm{in.}(12.7 \mathrm{~cm} \times 25 \mathrm{~cm})$ CSGO bandage over a $3 \mathrm{~mL}$ dried patch of $10 \mathrm{mg} / \mathrm{L}$ MB (top left). The bandage effectively covered the MB patch (top right). Upon removal of the bandage, most of the MB was removed and it was absorbed into the CSGO structure.

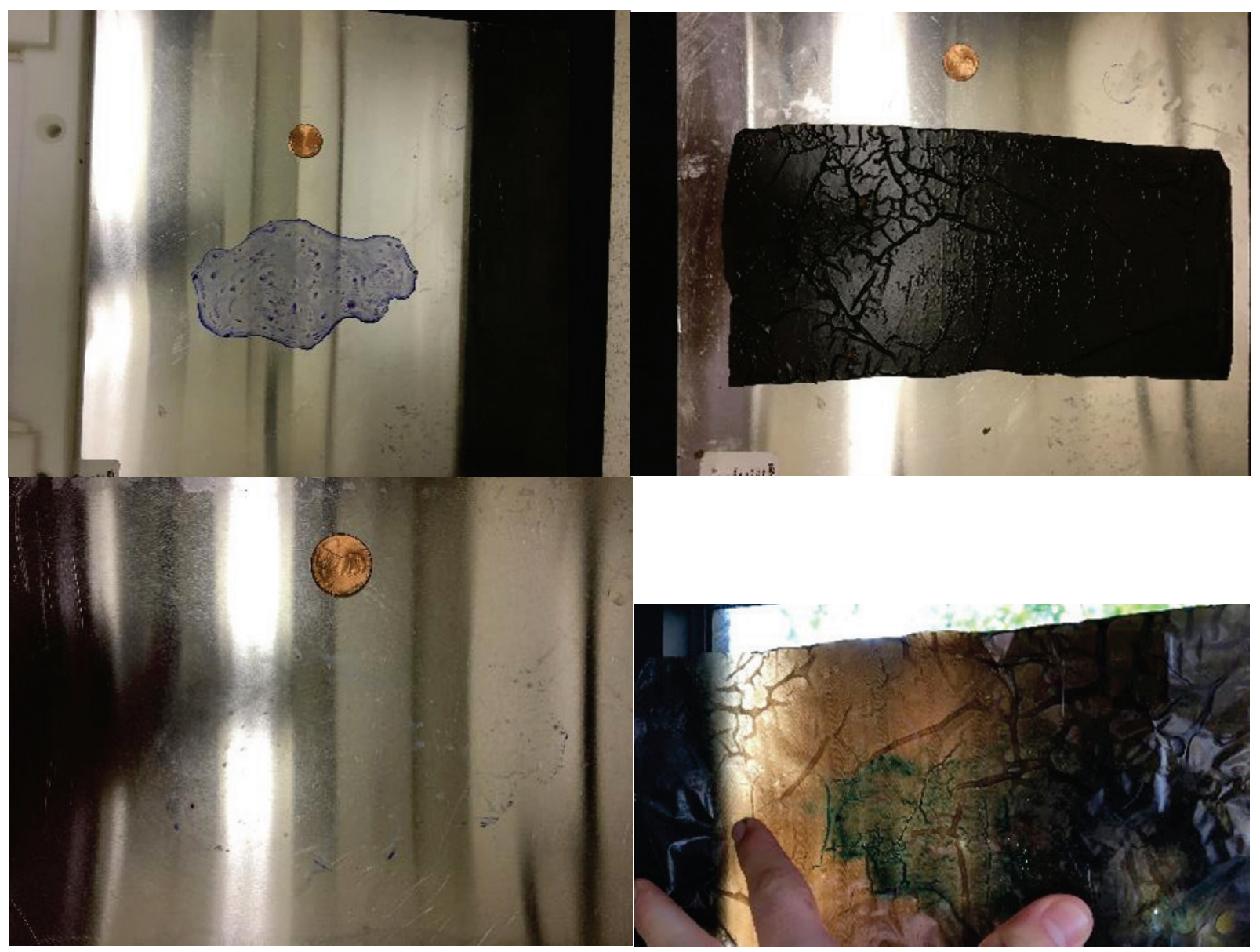

A question brought up by the study was "could we make a bandage just of chitosan (CS) that would work as well as the CSGO material?” To test this, a CS bandage was prepared using the same composition as the CSGO bandage, but without adding the GO component. The CS bandage shriveled up when applied, and it did not block the dissolution of $\mathrm{MB}$, nor did the bandage uptake the MB (Figure 5). Therefore, this control experiment indicated that GO was a necessary component to the bandage. 
Figure 5. CS Bandage showing unsuccessful application.

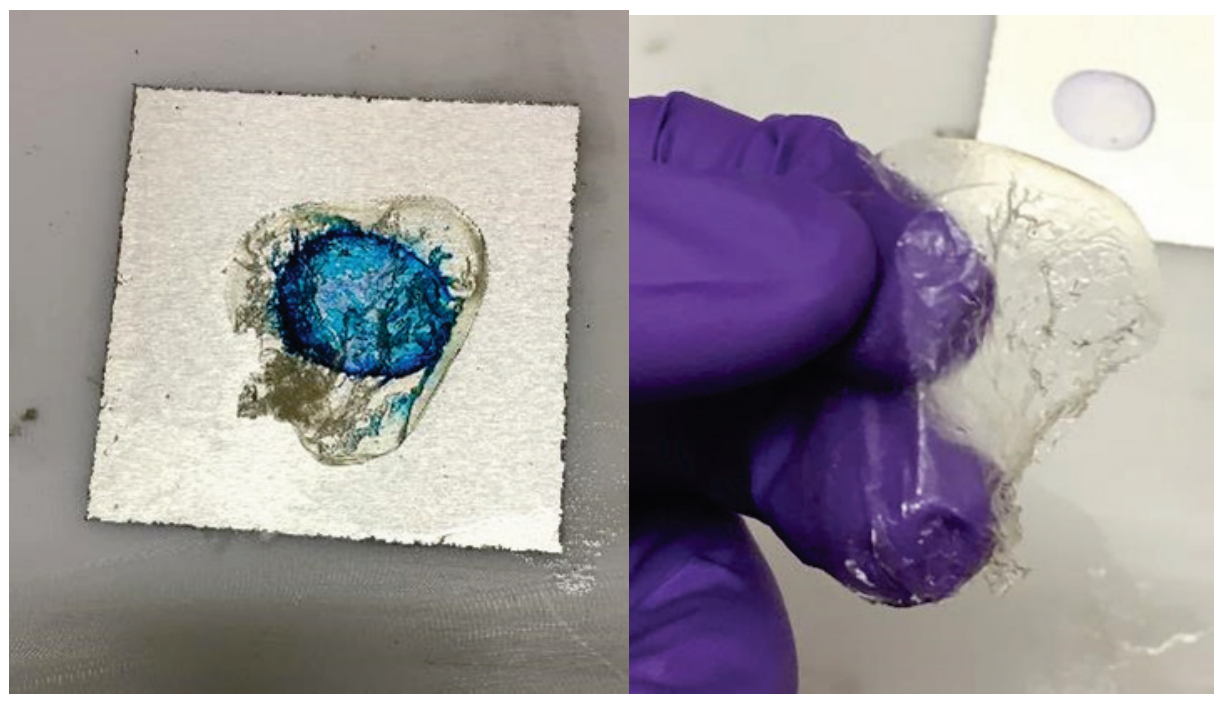

\subsubsection{Run off Experiment}

A run off experiment was conducted (Figure 6). This differed from the experiments described above in that the coupons were not submerged in solution, but had water poured on the coupons to investigate the removal of the MB by its runoff. Two, 2 in. $\mathrm{x} 2$ in. $(5 \mathrm{~cm} \times 5 \mathrm{~cm})$ aluminum coupons had $0.5 \mathrm{~mL}$ of $10 \mathrm{mg} / \mathrm{L} \mathrm{MB}$ applied, and were allowed to dry to form a patch on each. A 1.5 in. (3.8 cm diameter CSGO bandage was prepared from $3 \mathrm{~mL}$ of dispersion, then applied using the brush application described above to one of the aluminum coupons. The other coupon was left uncovered. The CSGO bandage dried for four hours and was then removed by peeling. Once again, upon bandage removal, most of the MB patch was eliminated (estimated over 95\%). 
Figure 6. Set up for the run off test. $0.5 \mathrm{~mL}$ of MB applied and allowed to dry to form contamination patches on two 2 in. $x 2$ in. $(5 \mathrm{~cm} \times 5 \mathrm{~cm})$ aluminum coupons. A 1.5 in. (3.8 $\mathrm{cm}$ ) diameter CSGO bandage was applied over the MB patch on one of the coupons (left). After four hours, the bandage was removed, removing most of the MB patch (right).

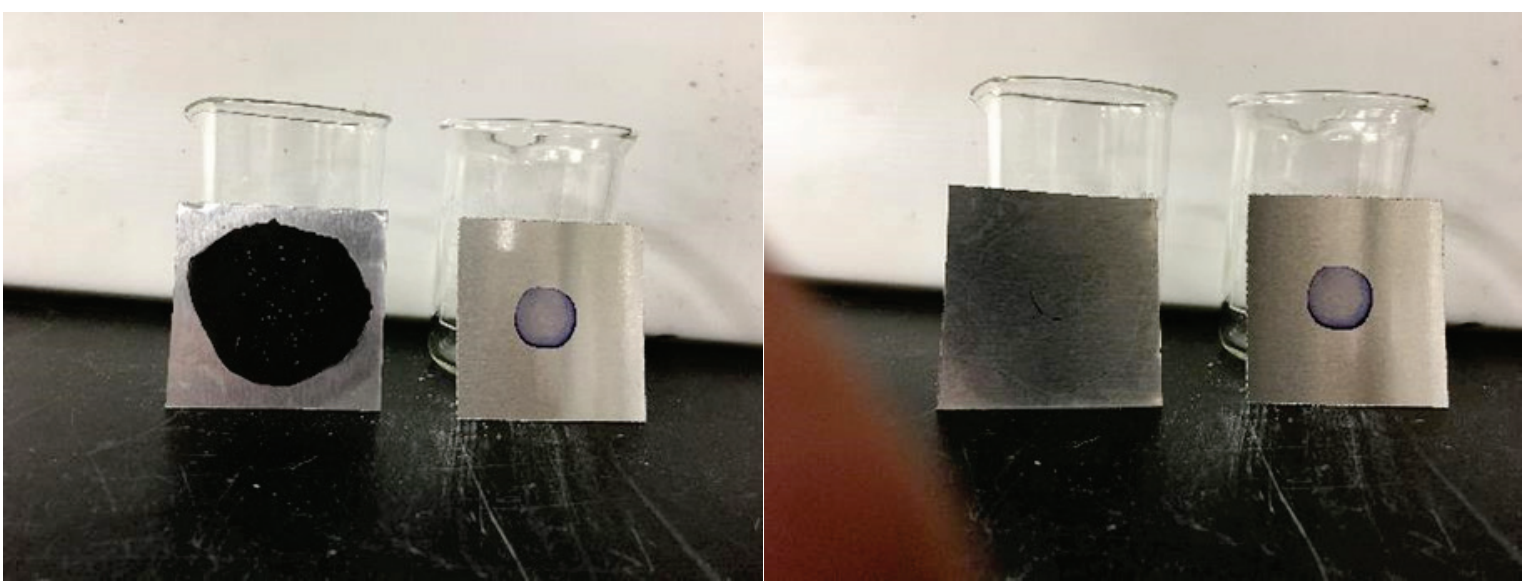

Following the setup, both coupons were rinsed with $20 \mathrm{~mL}$ of water, which was collected as run off (Figure 7). The run off of MB was then measured using a spectrophotometer. After rinsing, some of the MB patch was still retained on the coupon for both. There appeared to still be more MB retained on the untreated patch compared to that treated with the CSGO bandage. Run off of the MB in the untreated coupon measured 0.323 absorbance units (A), while this measured $0.000 \mathrm{~A}$ in the bandage treated coupon.

Figure 7. Results of the run off study.

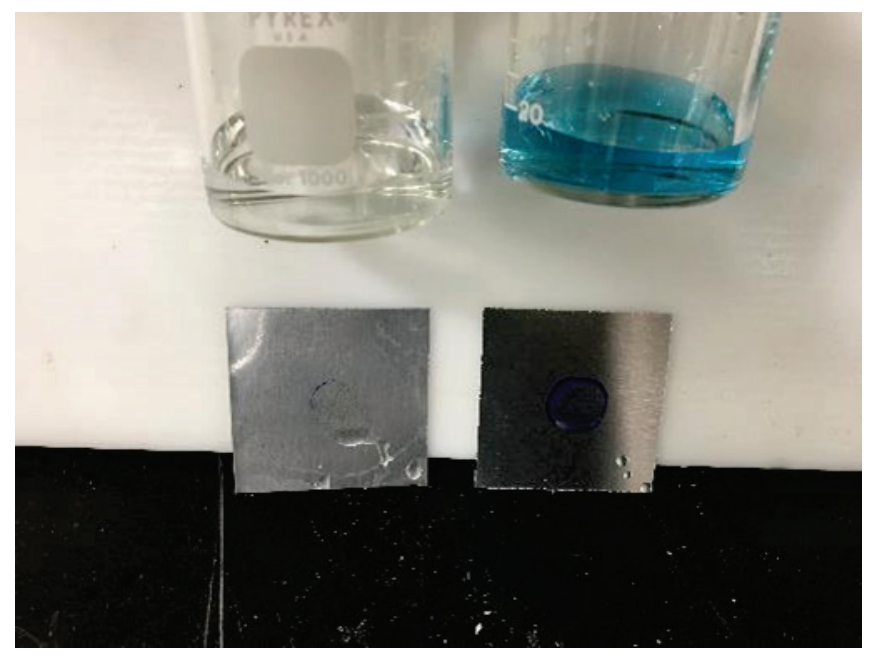




\subsubsection{Water submersion test}

The water submersion test used a similar setup as that for the run off test (see section 3.3) in that 2 in. $\mathrm{x} 2$ in. $(5 \mathrm{~cm} \times 5 \mathrm{~cm})$ aluminum coupons had $0.5 \mathrm{~mL}$ of $\mathrm{MB}$ applied and allowed to dry to form contaminant patches, and then one was covered by a 1.5 in. $(3.8 \mathrm{~cm})$ circular CSGO patch using the brush method. These were then submerged in $20 \mathrm{~mL}$ of deionized water.

The images in Figure 8 show that upon submersion, the MB began to dissolve off the untreated coupon, but no blue color was noticed in solution of the bandage treated coupon (upper left). After 24 hours, the blue color was distributed throughout the untreated sample (upper right, Figure 8). The bandage showed signs of decay as the black substance, presumably released GO, was found throughout the solution. However, no blue color was identified in the water.

The graph at the bottom of Figure 8 shows that the absorbance of MB for the untreated coupon (no CSGO) increased quickly over the first four hours, then continued to solubilize at a slower rate from 4-24 hours. The coupon with the CSGO bandage, on the other hand, had no measureable release of $\mathrm{MB}$, with the exception of a small measurement at four hours, which appears to have been a false positive or perhaps a transient result. 
Figure 8. Results of the submersion test.

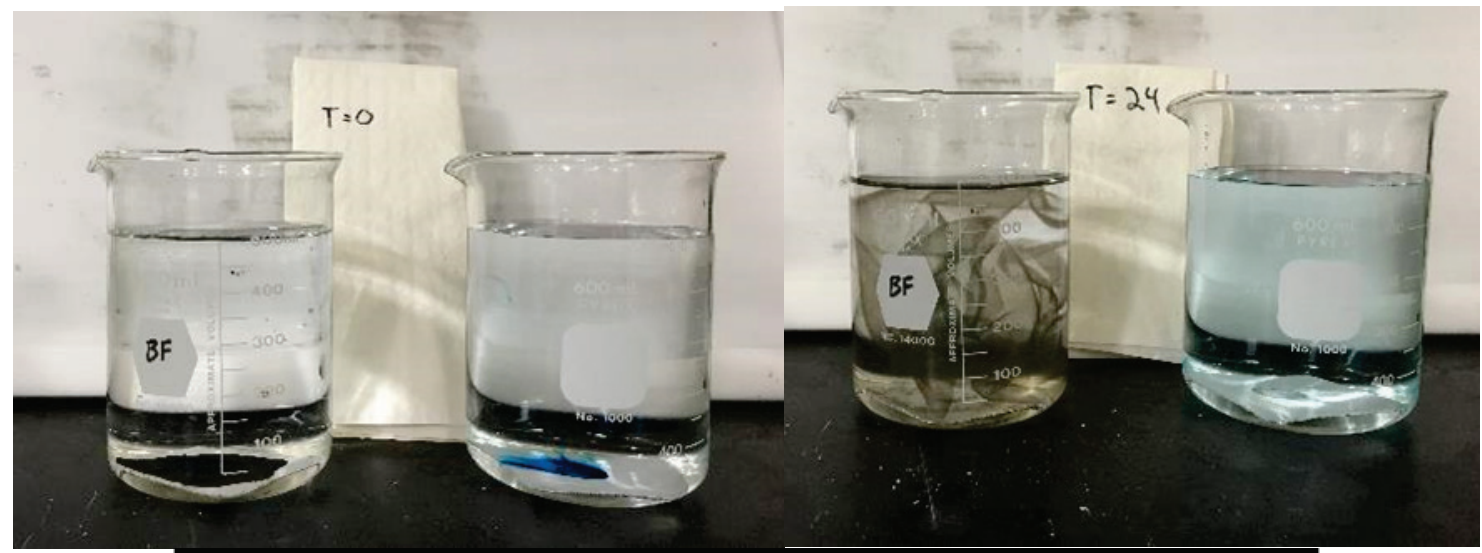

Submersion Spectrophotometer Results

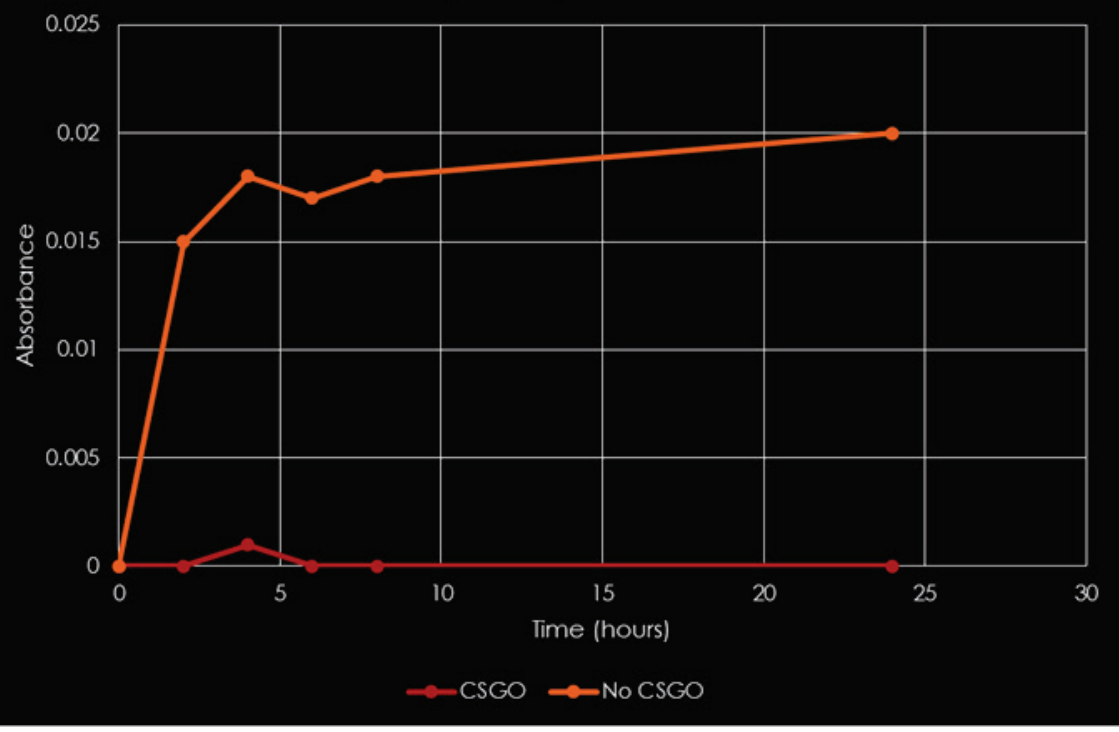

\subsection{Vehicle application studies}

Applications were conducted on three vehicle surfaces, a retired commuter van, a HUMVEE, and a M60A1 tank found on station (used with permission from the ERDC commander at the time, COL Bryan Green) (Figure 9).

Figure 9. Vehicles where bandage testing was conducted. Left - Doors from a retired commuter van, Middle - HUMVEE, Right - M60A1 tank.

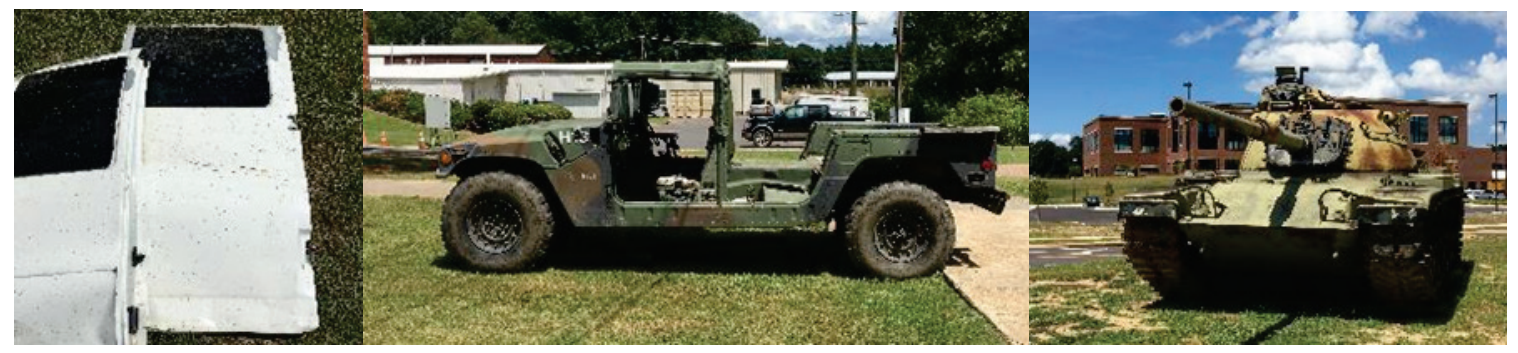




\subsubsection{Application on van door}

Although the van doors were found outdoors, they were a relatively clean surface, as they looked white with minimal amount of visible dirt or grime. A solution of $0.5 \mathrm{~mL}$ of $10 \mathrm{mg} / \mathrm{L} \mathrm{MB}$ was applied to the door and allowed to dry forming a contaminant patch (Figure 10). After drying, a 1.5 in. x 1.5 in. $(3.8 \mathrm{~cm} \times 3.8 \mathrm{~cm})$ CSGO bandage was applied to the surface using the brush technique, and was allowed to set for one hour. After one hour, the bandage was removed by peeling. Bandage removal was more difficult than in the clean coupon studies. When it was pulled off, a lot of small particles remained stuck to the surface. These were washed off. After this removal, some residual of the contaminant patch remained, however, over 90\% (estimated) of the MB contaminant was removed. Similar to the coupon studies, the MB adhered onto CSGO bandage after removal.

Figure 10. Photographs from the van door treatment study. Left - Application of $0.5 \mathrm{~mL}$ of $10 \mathrm{mg} / \mathrm{L} \mathrm{MB}$ to form a contaminant patch, Left middle - Application of a 1.5 in. $\times 1.5$ in. $(3.8 \mathrm{~cm} \times 3.8 \mathrm{~cm})$ CSGO bandage, Right middle - After removal of the patch, over $90 \%$ (estimated) of the MB contaminant was removed. Right - MB adhered onto CSGO bandage after removal.

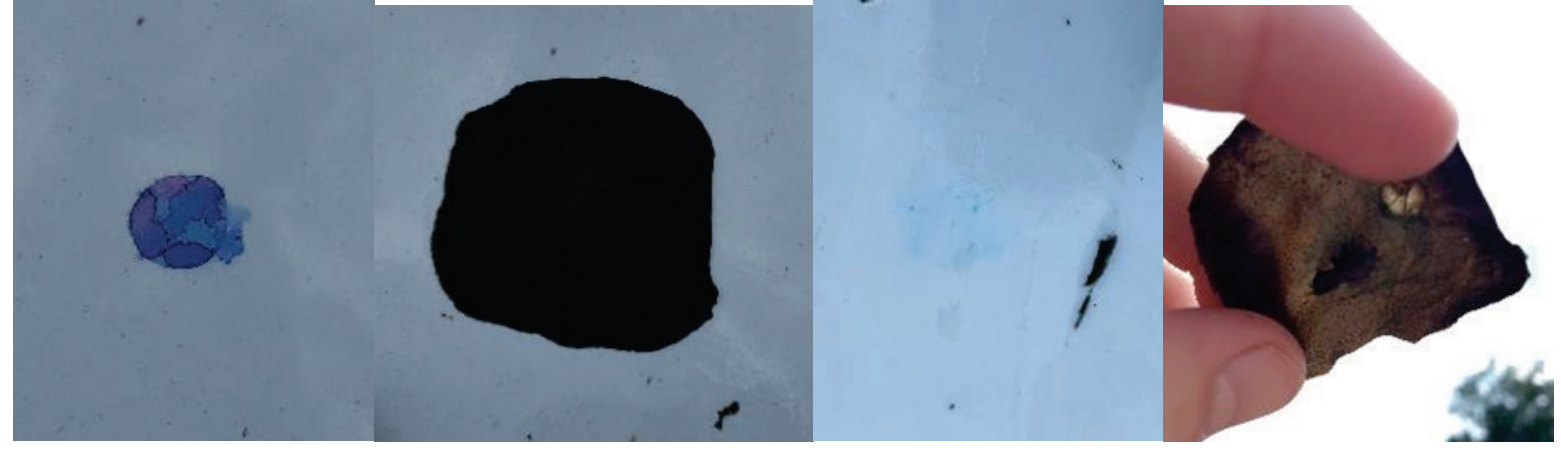

\subsubsection{Bandage treatment of a HUMVEE surface}

The setup for the HUMVEE study was the same for the van door. The surface of the HUMVEE was rough compared to the smooth surface of the van door, and it appeared to have more dirt and grime. When the $0.5 \mathrm{~mL}$ of $10 \mathrm{mg} / \mathrm{L} \mathrm{MB}$ was applied, it penetrated into the surface, leaving a much more dull color than when applied to the van door (Figure 11). Once again, a 1.5 in. $\times 1.5$ in. $(3.8 \mathrm{~cm} \times 3.8 \mathrm{~cm})$ bandage was applied. Removal of the dry bandage was difficult, but with some water applied to the surface, it peeled off relatively easy. A faint blue residual remained, with removal estimated in excess of $95 \%$. 
Figure 11. Photographs from the HUMVEE study. Left, shows the applied MB. Center, shows the bandage. Right, shows the spot after removal of the bandage.

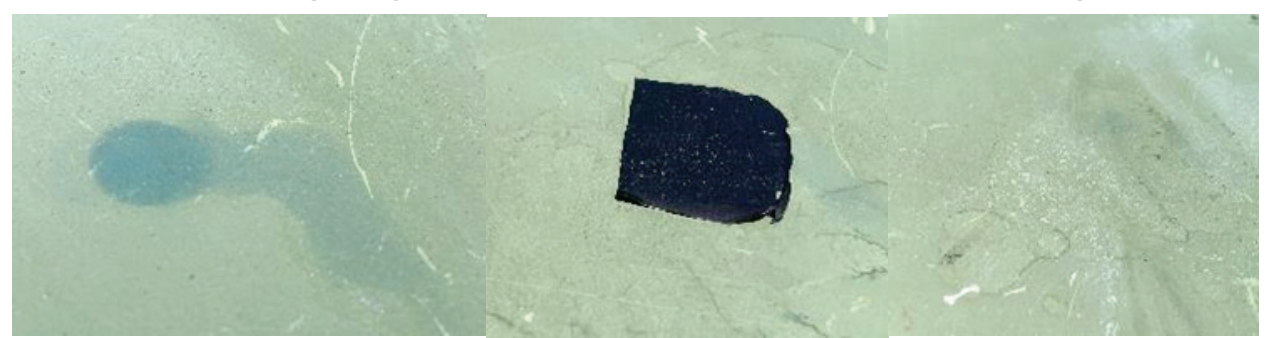

\subsubsection{Bandage treatment on M60A1 tank}

A bandage treatment an M6oA1 tank was conducted using $1 \mathrm{~mL}$ of 10 $\mathrm{mg} / \mathrm{L} \mathrm{MB}$ applied to form a contaminated patch (Figure 12). This was treated with a 2.5 in. $x 5$ in. $(6.4 \mathrm{~cm} \mathrm{x} 12.8 \mathrm{~cm}$ ) CSGO bandage applied using the brush method. Like the HUMVEE, the surface of the tank was rough and grimy. However, the MB did not appear to penetrate as deeply. The bandage covered the contamination and was left on for two hours. Upon removal, a faint amount of the MB remained on the tank surface, but most of it was removed (estimated over 90\%).

Figure 12. Application to tank surface. Left, is the applied MB material, Center, the bandage covering, and the Right, is the MB after the bandage removal showing a faint outline of the original applied MB.

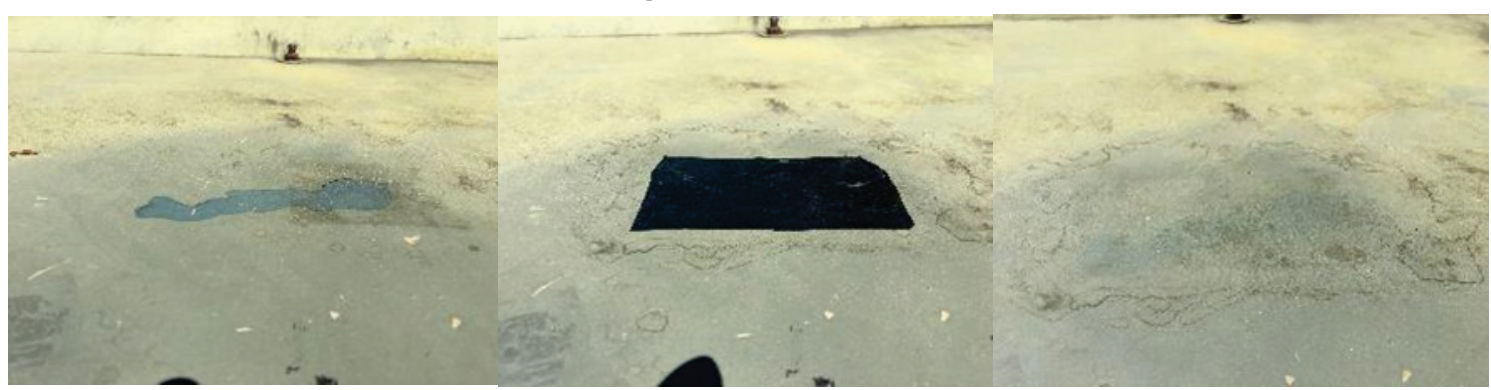




\section{Discussion}

These experiments indicate that the CSGO bandage is a potentially effective technique to return vehicles and equipment back into service quickly while using very little water. The bandage can be applied over the contaminated area and left in place, isolating the contaminant until it needs to be removed. Or, it can be applied and removed to eliminate most of the contaminant. These limited experiments showed that both methods are feasible, but it may be possible to enhance either the isolation or removal strategies. For example, a bandage could be designed to emphasize adhesion on the surface, enhancing the isolation aspect, or designed so that the layered aspect is enhanced, improving the removal aspect.

Wet and dry applications of the bandages were demonstrated. Wet applications might be more effective if there is enough time to let the solution set into a bandage as it would allow the solution to penetrate surface imperfections. However, dry applications can be done quickly and allow the vehicle to return to service faster.

This study was a screening effort to determine the efficacy of the bandage process. As such, it was effective. However, future studies could benefit from more robust measurement methods, such as the use gravimetric measurements to account for losses from contaminant dissolution, and the use of surface spectrographic methods that should allow detection of the blue color on surfaces. Future studies could also benefit from replication and statistical calculations.

The laboratory testing used unpainted aluminum pieces. The field demonstrations used vehicles or vehicle parts, and these were painted. The treatments on the vehicles were not as effective. Some factors may have been dirt and grime on the surfaces or unevenness. However, it is possible that the paint might have been a factor. Future benchtop testing could focus on comparison of painted coupons to unpainted ones.

The removal of the MB by the bandage appeared to be by absorptive incorporation into the bandage material. The blue color appeared to be inside the bandage structure. Further, the submersion study did not indicate any removal of the material incorporated in the bandage. 
These studies focused on MB as the contaminant. To be effective, the process must be effective using chemical warfare agents and other hazardous and toxic chemicals. Therefore, future studies could be conducted using actual agents, which may have some differences in their interactions with the CSGO materials. Characterization of the bandages after use would help to definitively determine the interfacing between the CSGO materials and the contaminant. Studies on chemical agent resistant coating (CARC) materials may also be useful. CARC are designed to allow less agent penetration (Bullivant 2004), so it is likely to enhance the removal approach with the bandages. 


\section{Conclusions}

The following conclusions were derived from this study:

- ERDC has adapted a CGSO material to sequester chemical materials on metal and painted surfaces.

- The bandage was effective at preventing the solubilization of MB into water from clean metal surfaces when submerged or rinsed.

- The bandage was also effective at rapidly absorbing MB from clean metal surfaces.

- Applications to vehicle surfaces were not as effective, but did result in a visible reduction of the MB that was adhered to the surface. 


\section{References}

Abolhassani, M., C. S. Griggs, L .A. Gurtowski, J. Mattei-Sosa, M. Nevins, V. F. Medina, T. A. Morgan, and L. F. Greenlee. 2018. Scalable chitosan-graphene oxide membranes: The effect of GO size on properties and cross-flow filtration performance. ACS Omega 2(12):8751-8759. Doi 10.1021/acsomega.7bo1266.

Brame, J., V. F. Medina, I. Smith, and L. Procell. 2016. Composition of CBRN Decontamination Effluent and Development of Surrogate Mixtures for Testing Effluent Treatment Technologies. Technical Report. ERDC-SR-16-2. Vicksburg, MS: U.S. Army Engineer Research and Development Center. http://acwc.sdp.sirsi.net/client/en_US/search/asset/1050948

Bullivant, T. 2004. Chemical Agent Resistant Coating (CARC). Next Generation Camouflage-More than meets the eye. MILSPRAY. Asbury Park, NJ. https://web.archive.org/web/20070221191915/http://www.milspray.com/CARC_Technical_P aper.pdf

Compton, R. R. 1962. Manual of Field Geology. New York, NY: John Wiley and Sons, Inc.

Disbrow, M., B. Mosier, S. Nedlic, and R. Simino. 2014. Hazard mitigation, material, and equipment restoration (HaMMER) advanced technology demonstration (ATD) joint military assessment. In 2011 IEEE International Conference on Technologies for Homeland Security (HST). Doi: 10.1109/THS.2011.6107867.

Joint Capabilities Board (JCB). 2011. Initial Capabilities Document for Joint Chemical, Biological Radiological and Nuclear Contamination Mitigation (ConMit). JROCM 031-11. Washington, DC: Joint Requirements Oversight Council.

Medina, V. F., C. S. Griggs, B. Petery, J. Mattei-Sosa, L. Gurtowski, S. A. Waisner, J. Blodget, and R. Moser. 2017. Fabrication, characterization, and testing of graphene oxide, and hydrophilic polymer graphene oxide composite membranes in a dead end flow system. Journal of Environmental Engineering. 143(11): doi: 10.1061/(ASCE)EE.1943-7870.0001268.

Medina, V. F., S. A Waisner, E. Martinez-Guerra, and J. A. Johnson. 2018a. Developing and Testing the Decontamination Effluent Treatment System. Army Chemical Review. PB 3-18-1.

Medina, V. F., S. A. Waisner, E. Martinez-Guerra, J. Johnson, J. Brame, E. Gao, and M. Page. 2018b. Simulated Vehicle Decontamination and Field Evaluation of the Decontamination Effluent Treatment System (DETS) and Associated Background Studies. ERDC TR-18-19. Vicksburg, MS: U.S. Army Engineer Research and Development Center.

Reid, J .C. 1985. Comparison chart of estimating volume percentages of constituents in rocks and concentrates in the range of 1 to 0.1 volume percent. American Mineralogist. 70:1318-1319. 


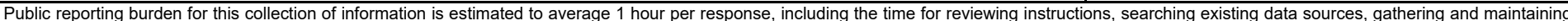

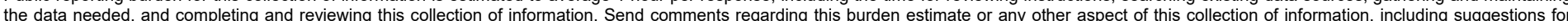

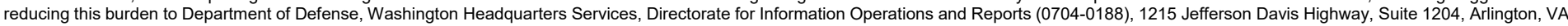

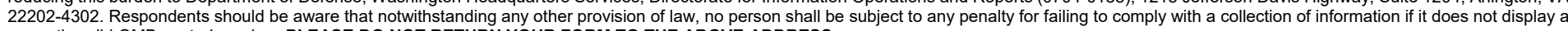
currently valid OMB control number. PLEASE DO NOT RETURN YOUR FORM TO THE ABOVE ADDRESS.
1. REPORT DATE (DD-MM-YYYY)
2. REPORT TYPE
3. DATES COVERED (From - To)

July 2019

Final report

\section{TITLE AND SUBTITLE}

Conceptual Development and Testing of a Chitosan/Graphene Oxide (CSGO) "Bandage" to Isolate and Remove Chemical Contamination from Surfaces

5a. CONTRACT NUMBER

5b. GRANT NUMBER

5c. PROGRAM ELEMENT NUMBER

\section{AUTHOR(S)}

Victor F. Medina, Chandler Noel, and Jose Mattei-Sosa

5d. PROJECT NUMBER

5e. TASK NUMBER

5f. WORK UNIT NUMBER

33143, P2 455017

\section{PERFORMING ORGANIZATION NAME(S) AND ADDRESS(ES)}

8. PERFORMING ORGANIZATION REPORT NUMBER

U.S. Army Engineer Research and Development Center

Environmental Laboratory

ERDC/EL TR-19-8

3909 Halls Ferry Road, Vicksburg, MS 39180-6199

Mississippi College

Department of Chemistry

200 Capitol Street

Clinton, MS 39056

9. SPONSORING / MONITORING AGENCY NAME(S) AND ADDRESS(ES)

Headquarters, U.S. Army Corps of Engineers

Washington, DC 20314-1000

10. SPONSOR/MONITOR'S ACRONYM(S)

USACE

11. SPONSOR/MONITOR'S REPORT NUMBER(S)

\section{DISTRIBUTION / AVAILABILITY STATEMENT}

Approved for public release; distribution unlimited.

\section{SUPPLEMENTARY NOTES}

\section{ABSTRACT}

This study describes the conceptual development and testing of a protective "bandage" prepared of a composite chitosan/graphene oxide (CSGO) material that can be applied over surfaces to isolate contamination, such as that occurring from a chemical weapon attack. The bandage can be applied either as a wet dispersion or as a dry, preset membrane. Dry bandage application can be implemented by wetting the material with acetic acid and setting on the surface, or the bandage can placed on the surface and acetic acid brushed over the bandage. The bandage isolates the contaminant by covering the contaminated area and preventing exposure, or by absorbing the contaminant into its structure. The bandage can then be removed, thereby, removing the contaminant. The efficacy of this approach was demonstrated with experiments on metal coupons using methylene blue as a simulant for a contaminant. Applications on government/military vehicles are also presented. The goal is to develop a means in which vehicles contaminated with chemical agents can be treated with minimal water and returned to service quickly without any spread of contamination or damage to the vehicle.

\section{SUBJECT TERMS}

Chitosan

Graphene

Composite materials
Chemical weapons--Decontamination Chemical agents (Munitions)

\section{SECURITY CLASSIFICATION OF:}

\section{a. REPORT}

UNCLASSIFIED

b. ABSTRACT
UNCLASSIFIED

c. THIS PAGE

UNCLASSIFIED
17. LIMITATION OF ABSTRACT

\section{NUMBER} OF PAGES 19a. NAME OF RESPONSIBLE PERSON

19b. TELEPHONE NUMBER (include

27 